Amani Osman Abdelmola ${ }^{1}$, Mohamed Salih Mahfouz ${ }^{1}$, Mona Ali Manssor Gahtani2 ${ }^{*}$,

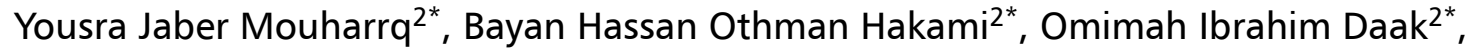
Aisha Qassem Alharbi ${ }^{2 *}$, Umklthom Mohammed Ali Masmali ${ }^{*}$, Dalal Ali Mohammed Melassy ${ }^{2 *}$, Afnan Ahmad Alhazmi ${ }^{2^{*}}$

${ }^{1}$ Department of Community Medicine, Faculty of Medicine, Jazan University, Jazan, Kingdom of Saudi Arabia

${ }^{2}$ Faculty of Medicine, Jazan University, Jazan, Kingdom of Saudi Arabia

*These authors contributed equally to this work

\title{
Gestational diabetes prevalence and risk factors among pregnant women - Jazan Region, Saudi Arabia
}

\section{ABSTRACT}

Background. The gestational diabetes (GDM) is considered as a global public health problem that affects pregnant women. GDM can become chronic type II and usually it is associated with many risk factors that may lead to many serious complications for the mother and the fetus. The main objective of this study was to estimate the prevalence of GDM among pregnant women in Jazan region and to determine the possible associated factors of the GDM.

Material and methods. The study involved pregnant women attending department of Obstetrics and Gynecology at government hospitals of Jazan region. A sample of 440 pregnant women were randomly selected. Interviews were conducted using a questionnaire prepared to measure the GDM prevalence, risk factors, awareness and adherence to the advice of the doctor and medications.

Results. The prevalence of gestational diabetes among pregnant women in Jazan is estimated at $8.2 \%$. The GDM prevalence was significantly higher among obese women (20.2\%; 95\% Cl 13.2-29.2) compared with women with normal weight (7.1\%; 95\% Cl 1.7-7.6).

Address for correspondence:

Mohamed Salih Mahfouz

Jazan University, Faculty of Medicine

e-mail: mm.mahfouz@gmail.com

Clinical Diabetology 2017, 6, 5, 172-177

DOI: $10.5603 /$ DK.2017.0028

Received: 07.06.2017

Accepted: 30.11.2017
The analysis showed that GDM was significantly associated with child weight more than $3.5 \mathrm{~kg}$ (OR 4.315; $\mathrm{p}=0.004)$, mother's BMI more than $30 \mathrm{~kg} / \mathrm{m}^{2}$ (OR 4.703; $p=0.001$ ), and family history of GDM (OR 2.606; $p=0.046$ ).

Conclusion. In conclusion, the GDM prevalence obtained in this study is more than global prevalence and less than other studies in KSA. The BMI of mothers and having neonates that weight more than $3.5 \mathrm{~kg}$ are the main risk factors for GDM. Suitable interventions programs are highly required for control and risk factor modifications. (Clin Diabetol 2017; 6, 5: 172-177)

Key words: gestational diabetes, obstetrics, hypoglycemia, Jazan

\section{Introduction}

Gestational diabetes is known as any degree of glucose intolerance with onset or first recognition during pregnancy. GDM causes high blood sugar that may affect the pregnancy and its outcome. Uncontrolled diabetes in early pregnancy leads to higher incidence of congenital anomalies of the fetus such as ventricular septal defect (VSD), neural tube defects (NTD) and Caudal Regression Syndrome (CRS) [1].

In the late pregnancy, uncontrolled diabetes leads to over-weight of fetus. Complications in fetus extends to fetal macrosomia, neonatal morbidity and mortality due to congenital anomalies, excessive fetal growth, respiratory distress syndrome, neonatal hypoglycemia 
and hypocalcemia, hypomagnesaemia, hyper bilirubinemia and polycythemia [2].

In most cases, gestational diabetes does not have symptoms, but increased urination, fatigue, nausea, vomiting, bladder infection and yeast infections can sometimes be present [3]. Poorly controlled glycaemia during pregnancy may lead to one of the followings complication of mother: abortion, poly-hydramnios, preterm labor, pre-eclampsia, placenta praevia, pruritus vulvae, urinary tract infection, puerperal sepsis and pyelonephritis [4].

The global profile of GDM suggests increasing prevalence during the past two decades, with large variabilities between different countries [5]. The estimated prevalence of GDM in many studies ranges between (1-20\%) [6]. Some of developed countries, like Canada has low prevalence of GDM of only $2.5 \%$ in 2001 which increased to 54.5 per 1,000 deliveries in $2010[7,8]$. In the USA, the prevalence ranges $3.9 \%$ to $12.8 \%$ [5]. In India study showed the prevalence of GDM is about $6.6 \%$ [9]. In the Qatar in 2010, study showed that the prevalence of GDM is about $16.3 \%$ [10]. The prevalence of GDM in Saudi Arabia ranges from $12.5 \%$ to $22.1 \%$ [11].

Different types of studies conducted in the different parts of the world to identify the main risk factors responsible for GDM. These studies summarized the risk factor to be: age above 35 years, overweight or obese women, recurrent abortion, neonatal death, pre-eclampsia, history of diabetes, high birth weight, caesarian section, multiple previous pregnancy $[12,13]$.

Many studies have been conducted in different parts of Saudi Arabia to examine the profile of GDM among pregnant women, but to our best of knowledge no previous study has been conducted in Jazan region. The main objectives of this study were to measure the prevalence of GDM among pregnant women in Jazan region and to determine the possible associated factors of GDM.

\section{Research methods}

Study area, design and population

This study was conducted in three selected general hospitals in Jazan region namely; Jazan general hospital, Abuarish general hospital and Sabya general hospital. Jazan region is located in the Southwest Saudi Arabia. It is one of the 13 regions of Saudi Arabia and populated with approximately 1.5 million population. Observational cross-sectional study was conducted to measure prevalence and risk factor of GDM among pregnant women attending obstetrics and gynecology departments in the selected three hospitals. The survey selected pregnant women in the reproductive age (15-49) in the $2^{\text {nd }}$ and $3^{\text {rd }}$ trimester during November 2014.

\section{Sampling method and sample size}

The proposed sample size for this study was calculated to be 440 . The calculation of the sample size was conducted on the assumptions that confidence level (95\%), margin of error not more than (5\%) and prevalence of GDM about (50\%), as no previous study is available in the region and finally non-response rate of $10 \%$.

\section{Procedures}

Generally, at the first antenatal visit, fasting plasma glucose (FPG), glycated hemoglobin $\left(\mathrm{HbA}_{1 \mathrm{c}}\right)$, and random plasma glucose were obtained from the pregnant women (initial screenings). Overt diabetes in pregnancy is diagnosed if; FPG $\geq 7.0 \mathrm{mmol} / \mathrm{L}(126 \mathrm{mg} / \mathrm{dL})$ or $\mathrm{HbA}_{1 \mathrm{c}}>6.5$ or random plasma glucose $\geq 11.1$ $\mathrm{mmol} / \mathrm{L}$ (200 mg/dL) plus confirmation. Screening of gestational diabetics for the women include one hour $50 \mathrm{~g}$ glucose challenge test (GCT), which is considered as the best method of screening, where patient usually not fasting prescribed oral 50 grams glucose. Blood sugar then measured, if $<7.8 \mathrm{mmol}$ (< $140 \mathrm{gms}$.), is considered normal. In case of GCT is normal, the test will be repeated at 24-28 weeks. If abnormal screening results $>140 \mathrm{mg}$, the patient is to have the diagnostic test which is oral glucose tolerance test. Diagnostic OGTT can be done either with $100-\mathrm{g}$ and 3 hours test or with $75 \mathrm{~g}$ and 2-hours test. Women who have had gestational diabetes in a previous pregnancy should be offered early self-monitoring of blood glucose or an OGTT at 16-18 weeks, and a further OGTT at 28 weeks if the results are normal. All pregnant patients attending for OGTT are instructed to fast from 12 midnight on the evening before their appointment [13].

\section{Data collection and study instrument}

The data was collected by interview "face to face" using a questionnaire designed for the purpose of the study. The questionnaire included open and closed ended questions, there were 25 questions classified into four parts personal data, prevalence and risk factors that leading to GDM, awareness about GDM and management of GDM. We conducted a pilot study by distributing 20 questionnaires and the main objective of this pilot test was to assess the components of the questionnaire, the understanding of study respondent about the questions and the time needed to answer the questionnaire. 


\section{Statistical analysis}

The overall GDM-prevalence among the study participants was calculated using $95 \%$ confidence intervals (Cl). The chi-square test or Fisher's exact test was used to evaluate the GDM-prevalence among the different sub-groups. Crude odds ratios (ORs) were obtained by univariate analysis to determine the association of each variable with GDM. All statistical tests were twosided; and a $\mathrm{p}<0.05$ was considered significant. The statistical analysis was performed using SPSS ver. 17.0 (SPSS Inc. Chicago, IL, USA) software.

\section{Ethical considerations}

Ethical approval for this study was obtained from the Ethics Committee of the Faculty of Medicine, Jazan University. Informed written consent was obtained from all participants prior to involvement in the study.

\section{Results}

Study participants including 440 females from the general hospitals (Sabya, Jazan, Abuarish). The majority of women were in the age group (21-25) and (26-30) years, $33.0 \%$ and $30.9 \%$ respectively. Nearly half of the women (48.9\%) are with high school education level. The large portion of women are women with normal body weight $(40 \%)$, obese were $(27.9 \%)$, while women in third trimester were (70\%) (Table 1).

Table 2 shows the prevalence GDM among pregnant women in Jazan region. The overall prevalence of GDM in Jazan region was $8.2 \%$ and significantly higher among those $>31-35$ years old. Prevalence was also significantly higher among obese women (20.2\%; $95 \% \mathrm{Cl} 13.2-29.2)$ compared with women with normal weight $(7.1 \% ; 95 \% \mathrm{Cl} 1.7-7.6)$. The prevalence of GDM among working women was $(8.3 \% ; 95 \% \mathrm{Cl} 29.8-49.7)$ versus non-working $(8.1 \% ; 95 \% \mathrm{Cl}, 2.7-7.9)$ and Saudi (8.6\%; 95\% Cl 4.2-16.2) versus non-Saudi population (5.4\%; 95\% Cl 5.7-11.4).

Table 3 shows the association between certain factors and GDM prevalence among pregnant women in Jazan population. The prevalence was significantly associated with family history of GDM, child weight greater than $3.5 \mathrm{~kg}$, mother's BMI greater than 30. No significant association was found between GDM prevalence and number of pregnancies more than three children and mother's age greater than 35 years.

Table 4 illustrates the results of the multivariate logistic regression analysis. The analysis showed that GDM prevalence was significantly associated with child weight more than $3.5 \mathrm{~kg}$ (OR 4.315; $\mathrm{p}=0.004)$, mother's BMI more than $30 \mathrm{~kg} / \mathrm{m}^{2}$ (OR 4.703; $\mathrm{p}=0.001$ ), and family history of GDM (OR 2.606; $p=0.046)$.
Table 1. Demographic profile of the study population

\begin{tabular}{|c|c|c|}
\hline Characteristic & $\mathrm{N}$ & $\%$ \\
\hline \multicolumn{3}{|l|}{ Age group (years) } \\
\hline $15-20$ & 48 & 10.9 \\
\hline $21-25$ & 145 & 33.0 \\
\hline $26-30$ & 136 & 30.9 \\
\hline $31-35$ & 76 & 17.3 \\
\hline $36-50$ & 35 & 8.0 \\
\hline \multicolumn{3}{|l|}{ Educational level } \\
\hline Primary & 49 & 11.1 \\
\hline Intermediate & 42 & 9.5 \\
\hline Secondary & 93 & 21.1 \\
\hline High school & 215 & 48.9 \\
\hline None & 41 & 9.3 \\
\hline \multicolumn{3}{|l|}{ Nationality } \\
\hline Saudi & 384 & 87.3 \\
\hline Non-Saudi & 56 & 12.7 \\
\hline \multicolumn{3}{|l|}{ Occupation } \\
\hline Working & 84 & 19.1 \\
\hline Not working & 356 & 80.9 \\
\hline \multicolumn{3}{|l|}{ BMI categories } \\
\hline Underweight & 47 & 10.8 \\
\hline Normal weight & 177 & 40.7 \\
\hline Overweight & 88 & 20.2 \\
\hline Obesity & 123 & 28.3 \\
\hline \multicolumn{3}{|l|}{ Pregnant month } \\
\hline Second trimester 4-5-6 & 131 & 29.8 \\
\hline Third trimester 7-8-9 & 308 & 70.2 \\
\hline Total & 440 & 100 \\
\hline
\end{tabular}

Figure 1 presents some variables related to GDM management among pregnant women with GDM. According to the figure, $81 \%$ of women were well adherent to doctor advice. The same figure lustrates that about one third of women were practicing exercise (34\%). Seventy percent of the women were following proper diet, while $44 \%$ are regular checking up their blood sugar level at home.

\section{Discussion}

Our paper suggests that the prevalence of GDM is estimated at $8.2 \%(95 \% \mathrm{Cl} 6.0-11.1)$, which is lower that most studies conducted in Saudi Arabia [6, 14, 15]. Literature generally suggested high variability of GDM, this may be attributed to discrepancies in GDM prevalence estimates by data sources and for a consensus on which diagnostic criteria to use.

Our study revealed that the prevalence of GDM was higher among women in the age group (31-35) years. Many studies suggested that it is normally high among 
Table 2. Prevalence of GDM among pregnant women in Jazan, Saudi Arabia

\begin{tabular}{|c|c|c|c|c|}
\hline Characteristic & GDM positive/ N-tested & Prevalence & $95 \% \mathrm{Cl}$ & P-value \\
\hline \multicolumn{5}{|l|}{ Age group (years) } \\
\hline $15-20$ & $(6 / 48)$ & 12.5 & $(5.9-24.8)$ & 0.033 \\
\hline $21-25$ & $(3 / 145)$ & 2.1 & $(0.8-5.9)$ & \\
\hline $26-30$ & $(13 / 136)$ & 9.6 & $(5.7-15.7)$ & \\
\hline $31-35$ & $(10 / 76)$ & 13.2 & $(7.3-22.6)$ & \\
\hline $36-50$ & $(4 / 35)$ & 11.4 & $(4.7-26.0)$ & \\
\hline \multicolumn{5}{|l|}{ Educational level } \\
\hline None & $(2 / 41)$ & 4.9 & $(1.5-16.2)$ & 0.011 \\
\hline Primary & $(3 / 49)$ & 6.1 & $(2.2-16.5)$ & \\
\hline Intermediate & $(8 / 42)$ & 19.0 & $(16.0-33.4)$ & \\
\hline Secondary & $(12 / 93)$ & 12.9 & $(7.5-21.2)$ & \\
\hline High school & $(11 / 215)$ & 5.1 & $(2.9-8.9)$ & \\
\hline \multicolumn{5}{|l|}{ Work status } \\
\hline Working & $(7 / 84)$ & 8.3 & $(29.8-49.7)$ & 0.550 \\
\hline Not working & $(29 / 356)$ & 8.1 & $(2.7-7.9)$ & \\
\hline \multicolumn{5}{|l|}{ Nationality } \\
\hline Saudi & $(33 / 384)$ & 8.6 & $(4.2-16.2)$ & 0.300 \\
\hline Non-Saudi & $(3 / 56)$ & 5.4 & $(5.7-11.4)$ & \\
\hline \multicolumn{5}{|l|}{ BMI $\left[\mathrm{kg} / \mathrm{m}^{2}\right]$} \\
\hline Underweight & $(3 / 26)$ & 16.4 & $(4.2-29.1)$ & 0.000 \\
\hline Normal weight & $(6 / 166)$ & 7.1 & $(1.7-7.6)$ & \\
\hline Overweight & $(9 / 150)$ & 6.0 & $(3.2-11.0)$ & \\
\hline Obesity & $(18 / 89)$ & 20.2 & $(13.2-29.2)$ & \\
\hline Overall prevalence & $(36 / 440)$ & 8.2 & $(6.0-11.1)$ & \\
\hline
\end{tabular}

Table 3. Risk factors associated with GDM among pregnant women Jazan, Saudi Arabia

\begin{tabular}{|c|c|c|c|c|}
\hline Factor & N (\%) GDM positive & N (\%) GDM negative & OR $(95 \% \mathrm{Cl})$ & P-value \\
\hline \multicolumn{5}{|c|}{ Family history of GDM $(n=440)$} \\
\hline Yes & $15(17.9)$ & $69(82.1)$ & $3.50(1.70-7.1)$ & 0.000 \\
\hline No & $21(5.9)$ & $335(94.1)$ & & \\
\hline \multicolumn{5}{|l|}{ Child weight $(n=306)$} \\
\hline More than $3.5 \mathrm{~kg}$ & $10(25.0)$ & $30(75.0)$ & $5.5(2.3-16.2)$ & 0.000 \\
\hline Less than $3.5 \mathrm{~kg}$ & $15(5.6)$ & $251(94.4)$ & & \\
\hline \multicolumn{5}{|c|}{ Number of Pregnancies $(n=440)$} \\
\hline 3 or less & $21(7.2)$ & $271(92.8)$ & $1.03(0.97-1.10)$ & 0.287 \\
\hline More than 3 & $15(10.1)$ & $133(89.9)$ & & \\
\hline \multicolumn{5}{|l|}{ Mother's BMI $(n=440)$} \\
\hline Less than $29.9 \mathrm{~kg} / \mathrm{m}^{2}$ & $18(5.2)$ & $329(94.8)$ & $1.17(1.01-1.3)$ & 0.000 \\
\hline $30 \mathrm{~kg} / \mathrm{m}^{2}$ and above & $18(19.4)$ & $75(80.6)$ & & \\
\hline \multicolumn{5}{|l|}{ Mother's age $(n=440)$} \\
\hline Less than 35 years & $32(7.9)$ & $373(92.1)$ & $1.04(0.92-1.17)$ & 0.465 \\
\hline 35 years and more & $4(11.4)$ & $31(88.6)$ & & \\
\hline
\end{tabular}

age groups higher than 35 years $[7,10,11,16-19]$. The prevalence of GDM distribution by educational levels showed that it is high among women with intermediate educational level, this somehow different from other stud- ies like Bangladesh study, where GDM was found to be higher among women with higher education level [17].

Regarding the risk factors of gestational diabetes, we found a significant association between obesity 
Table 4. Results of the multivariate logistic regression analysis assessing GDM risk factors

\begin{tabular}{|c|c|c|c|c|c|c|}
\hline \multirow[t]{2}{*}{ Risk factors } & \multirow[t]{2}{*}{ S.E. } & \multirow[t]{2}{*}{ Wald } & \multirow[t]{2}{*}{ P-value } & \multirow[t]{2}{*}{ OR } & \multicolumn{2}{|c|}{$95 \% \mathrm{Cl}$ OR } \\
\hline & & & & & Lower & Upper \\
\hline Family history of GDM & 0.479 & 3.999 & 0.046 & 2.606 & 1.019 & 6.662 \\
\hline Child weight more than $3.5 \mathrm{~kg}$ & 0.516 & 8.034 & 0.005 & 4.315 & 1.570 & 11.859 \\
\hline Pregnancies more than 3 & 0.492 & 0.003 & 0.959 & 0.975 & 0.372 & 2.558 \\
\hline Mother's BMI more than $30 \mathrm{~kg} / \mathrm{m}^{2}$ & 0.458 & 11.423 & 0.001 & 4.703 & 1.916 & 11.541 \\
\hline Mother's age more than 35 years & 0.769 & 0.804 & 0.370 & 1.993 & 0.441 & 9.000 \\
\hline
\end{tabular}

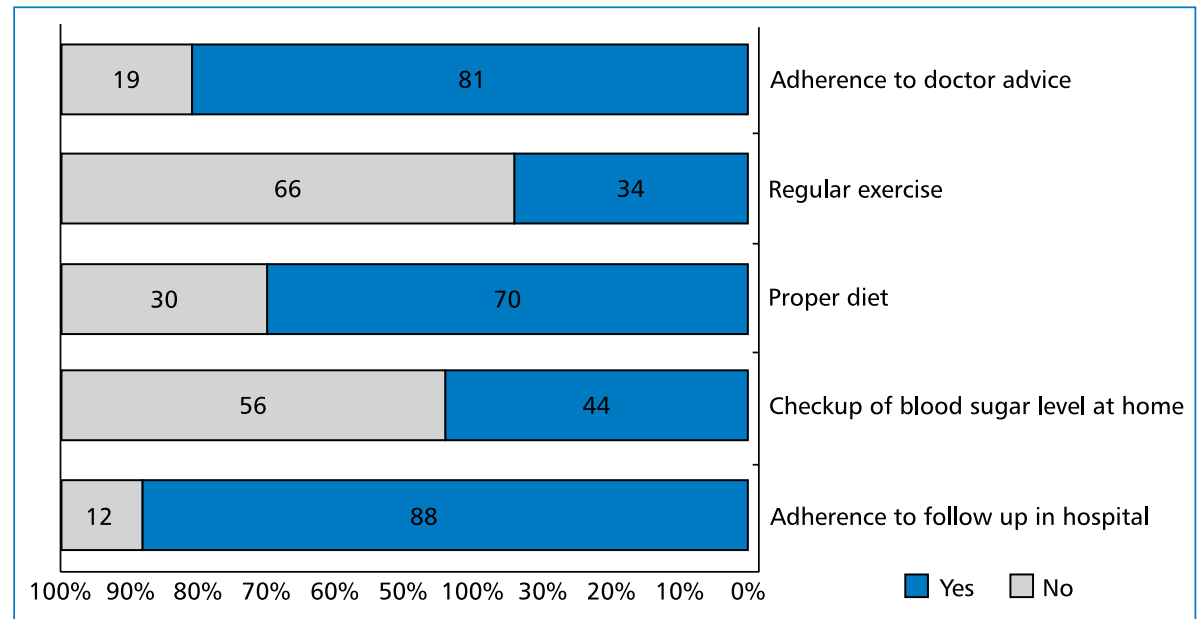

Figure 1. Management of GDM among pregnant women

and GDM, also history of diabetes, high birth weight and ageing. Comparing with other studies conducted in Canada, Sirlanka and Italy, we found similar or close results to our study $[7,12,19]$.

The percentage of pregnant women who were following diet advice was $70.0 \%$ of the GDM mothers, while the percentage of GDM women who are adherent to instructions of doctors is $81.0 \%$. Also, the percentage of pregnant women who are performing exercise is $34.0 \%$. Life style change is very important for women with GDM, as studies showed that changing life style decreases the probability of type 2 DM among GDM women [20]. Shek, et al. 2014 in their randomized intervention study showed that lifestyle intervention can reduce the development of type $2 \mathrm{DM}$ and metabolic syndrome among Chinese women who had GDM.

Our study has some limitations; first as participants of this study were limited to women attending general hospitals of Jazan region, the results may only apply to women visiting general hospitals of the same profile. The cross-sectional nature of the study is another limitation, associations from this study should be understood with in this context. However, to our best knowledge the present study is the first study investigating the issue of GDM in Jazan region and the study outcomes supposed to provide a quick picture about the situation of GDM in the area.

\section{Conclusion and recommendations}

In conclusion, the GDM prevalence obtained in this study is $8.2 \%$, which is more than global prevalence and less than other cities in KSA. The body mass index of mothers and having neonates that weight more than $3.5 \mathrm{~kg}$ are the main risk factors for gestational diabetes mellitus in Jazan region. Given what we have mentioned, we strongly recommend increase of women awareness about GDM and promoting a healthy life-style interventions for preventing GDM and improving pregnant women quality of life.

\section{Acknowledgments}

Special thanks to Dr. Hussam Eldin Elsawi, Dr. Hala M Kheir and Dr. Ali El-Shabrawy, for their help. Also, thanks for the pregnant women who sacrificed their valuable time and take active part of the study give us time for answering our questionnaire and General hos- 
pital that help us to collect data from their patient. We thank also the university specially faculty of medicine for the agreement and kind for doing our research.

\section{Conflict of interest}

The authors have no conflicts of interest.

\section{Author contributions}

Authors contributed equally to this work.

\section{REFERENCES}

1. Zaw W, Stone DG. Caudal Regression Syndrome in twin pregnancy with type II diabetes. J Perinatol. 2002; 22(2): 171-174, doi: 10.1038/sj.jp.7210614, indexed in Pubmed: 11896527.

2. Perkins JM, Dunn JP, Jagasia SM. Perspectives in Gestational Diabetes Mellitus: A Review of Screening, Diagnosis, and Treatment. Clinical Diabetes. 2007; 25(2): 57-62, doi: 10.2337/ /diaclin.25.2.57.

3. Lawal M. Management of diabetes mellitus in clinical practice. Br J Nurs. 2008; 17(17): 1106-1113, doi: 10.12968/ /bjon.2008.17.17.31109, indexed in Pubmed: 19186366.

4. Moy FM, Ray A, Buckley BS, et al. Techniques of monitoring blood glucose during pregnancy for women with pre-existing diabetes. Cochrane Database Syst Rev. 2014; 6(4): CD009613, doi: 10.1002/14651858.CD009613.pub2, indexed in Pubmed: 24782359.

5. Hunt KJ, Schuller KL. The increasing prevalence of diabetes in pregnancy. Obstet Gynecol Clin North Am. 2007; 34(2): 173-99, vii, doi: 10.1016/j.ogc.2007.03.002, indexed in Pubmed: 17572266.

6. Alfadhli EM. Gestational diabetes mellitus. Saudi Med J. 2015; 36(4): 399-406, doi: 10.15537/smj.2015.4.10307, indexed in Pubmed: 25828275 .

7. Xiong X, Saunders LD, Wang FL, et al. Gestational diabetes mellitus: prevalence, risk factors, maternal and infant outcomes. Int J Gynaecol Obstet. 2001; 75(3): 221-228, doi: 10.1016/s00207292(01)00496-9, indexed in Pubmed: 11728481.

8. The Public Health Agency of Canada's Maternal diabetes in Canada fact sheet. Canadian Perinatal Surveillance System monitors and reports on key indicators of maternal, fetal and infant health in Canada 2014. https://www.canada.ca/en/public-health/ /services/publications/healthy-living/maternal-diabetes-canada. html, accessed January 2017 (January 2017)

9. Kalra $\mathrm{P}$, Kachhwaha $\mathrm{CP}$, Singh HV. Prevalence of gestational diabetes mellitus and its outcome in western Rajasthan. Indian
J Endocrinol Metab. 2013; 17(4): 677-680, doi: 10.4103/22308210.113760, indexed in Pubmed: 23961485.

10. Bener A, Saleh NM, Al-Hamaq A. Prevalence of gestational diabetes and associated maternal and neonatal complications in a fast-developing community: global comparisons. Int J Womens Health. 2011; 3: 367-373, doi: 10.2147/IJWH.S26094, indexed in Pubmed: 22140323.

11. Al-Rowaily MA, Abolfotouh MA. Predictors of gestational diabetes mellitus in a high-parity community in Saudi Arabia/Facteurs predictifs du diabete gestationnel au sein d'une communaute a parite elevee en Arabie saoudite. Eastern Mediterranean Health Journal. 2010; 16(6): 636

12. Di Cianni G, Volpe L, Lencioni C, et al. Prevalence and risk factors for gestational diabetes assessed by universal screening. Diabetes Res Clin Pract. 2003; 62(2): 131-137, doi: 10.1016/j. diabres.2003.07.004, indexed in Pubmed: 14581150.

13. American Diabetes Association. Gestational diabetes mellitus. Diabetes Care. 2014; 37(Suppl 1): 14-80.

14. Serehi AAl, Ahmed AM, Shakeel F, et al. A comparison on the prevalence and outcomes of gestational versus type 2 diabetes mellitus in 1718 Saudi pregnancies. Int J Clin Exp Med. 2015; 8(7): 11502-11507, indexed in Pubmed: 26379970.

15. Al-Rubeaan K, Youssef AM, Subhani SN, et al. Diabetic nephropathy and its risk factors in a society with a type 2 diabetes epidemic: a Saudi National Diabetes Registry-based study. PLoS One. 2014; 9(2): e88956, doi: 10.1371/journal.pone.0088956, indexed in Pubmed: 24586457.

16. Macaulay S, Dunger DB, Norris SA. Gestational diabetes mellitus in Africa: a systematic review. PLoS One. 2014; 9(6): e97871, doi: 10.1371/journal.pone.0097871, indexed in Pubmed: 24892280.

17. Jesmin $\mathrm{S}$, Akter $\mathrm{S}$, Akashi $\mathrm{H}$, et al. Screening for gestational diabetes mellitus and its prevalence in Bangladesh. Diabetes Res Clin Pract. 2014; 103(1): 57-62, doi: 10.1016/j.diabres.2013.11.024, indexed in Pubmed: 24369985.

18. Hadaegh F, Tohidi M, Harati $\mathrm{H}$, et al. Prevalence of gestational diabetes mellitus in southern Iran (Bandar Abbas City). Endocr Pract. 2005; 11(5): 313-318, doi: 10.4158/EP.11.5.313, indexed in Pubmed: 16191491.

19. Dornhorst A, Rossi M. Risk and prevention of type 2 diabetes in women with gestational diabetes. Diabetes Care. 1998; 21 Suppl 2: B43-B49, indexed in Pubmed: 9704226.

20. Shek NW, Ngai CS, Lee $C P$, et al. Lifestyle modifications in the development of diabetes mellitus and metabolic syndrome in Chinese women who had gestational diabetes mellitus: a randomized interventional trial. Arch Gynecol Obstet. 2014; 289(2): 319-327, doi: 10.1007/s00404-013-2971-0, indexed in Pubmed: 23897066. 